\title{
Hydrodynamics in a Pressurized Cocurrent Gas-liquid Trickle-bed Reactor
}

\author{
Wino J.A. Wammes and K. Roel Westerterp*
}

The influence of gas density on total external liquid hold-up, pressure drop and gas-liquid interfacial area, under trickle-flow conditions, and the transition to pulse flow have been investigated with nitrogen or helium as the gas phase up to $7.5 \mathrm{MPa}$. It is concluded that the hydrodynamics depends on the gas density and not on the reactor pressure. At higher gas densities, the operating region for trickle flow becomes larger while the gas-liquid interfacial area increases only slightly. Pressure gradient and liquid hold-up are considerably affected by gas density and correlations have been derived for these parameters.

\section{Introduction}

In the gas-liquid trickle-bed reactor, the liquid phase always flows downward through the packed bed, whereas the gas phase can flow either upward or downward. The countercurrent operation is often preferred for physical absorption and desorption processes. In this case, flooding can occur, in contrast to the cocurrent downflow operation where there are no limitations to the gas and liquid throughputs. The cocurrent trickle-flow reactor is used for processes in which a gaseous component is removed by a chemical reaction in the liquid phase, as in chemical absorption processes, or by heterogeneously catalyzed reactions. The cocurrent gas-liquid catalytic trickle-bed reactor is widely applied in the petrochemical and chemical industries, mostly for hydrogenation and oxidation reactions, e.g. in catalytic hydrotreating or oxidative waste water treatment. The commercial cocurrent trickle-bed reactors normally operate adiabatically and with superficial gas and liquid velocities of up to $30 \mathrm{~cm} / \mathrm{s}$ and 0.8 $\mathrm{cm} / \mathrm{s}$, respectively. To increase the concentration of the gaseous reactant in the liquid phase, nearly all commercial processes are performed at elevated pressures of up to between 20 and $30 \mathrm{MPa}$.

A large amount of research has been published on various hydrodynamic aspects, such as liquid hold-up, pressure drop, flow regime transitions, liquid phase residence time distribution, catalyst wetting and gas-liquid and liquid-solid mass transfer. It can be concluded from these studies that hydrodynamic phenomena are influenced by the superficial gas and liquid velocities, the type of packing and the physical properties of the liquid phase. Many empirical relationships, flow charts, correlations and model equations are available for use in design calculations. However, it should be realized that all the studies published on hydrodynamics have been performed only under atmospheric conditions. Since most industrial trickle-bed applications occur at elevated pressures, knowledge of possible effects of reactor pressure on hydrodynamics is indispensable.

* Prof. Dr. Ir. K.R. Westerterp (author to whom correspondence should be addressed) and Dr. Ir. W.J.A. Wammes, University of Twente, Department of Chemical Engineering, Chemical Reaction Engineering Laboratories, PO Box 217, 7500 AE Enschede, the Netherlands. Present address of Dr. Ir. W.J.A. Wammes: BASF AG, Ludwigshafen/ $\mathrm{Rh}$.
This paper presents the results of experimental study on the influence of pressure on the total external liquid hold-up, i.e. the liquid hold-up in the void volume between catalyst particles, pressure drop, flow regime transitions and gas-liquid interfacial areas per unit volume in the cocurrent gas-liquid trickle-bed reactor.

The experimental study was performed with non-foaming systems at operating pressures of up to $7.5 \mathrm{MPa}$ and with gas and liquid velocities, comparable to industrial conditions. Apart from the variation of reactor pressure, two gases of different molar masses, nitrogen and helium, were used to vary the gas density. In cocurrent catalytic trickle-bed reactors, relatively small packing particles, typically of $d_{\mathrm{p}}<4 \mathrm{~mm}$, are used, mostly with spherical or cylindrical geometry. Our investigations were carried out in a packed bed of non-porous $3 \pm 0.5 \mathrm{~mm}$ glass spheres or of porous $3.2 \times 3.2 \mathrm{~mm}$ alumina cylinders. Literature data mostly refer to water and air under atmospheric conditions. The hydrodynamic studies were performed with demineralized water as well as with ethanol, which has a low gas-liquid surface tension, and also with viscous aqueous ethylene glycol (ETG) solution. The gas-liquid interfacial areas per unit volume were determined via chemically enhanced absorption of carbon dioxide in an aqueous amine solution or in viscous aqueous ethylene glycol. Nitrogen was used as the carrier gas for these absorption experiments.

\section{Experimental Set-up and Procedures}

Here, we provide only a brief description of the set-up and methods. More details can be found in Wammes et al. [1, 2].

\subsection{Gas-liquid Interfacial Area}

The gas-liquid interfacial area was determined by a chemical method. A gas phase component A was absorbed into a liquid phase, where it reacted irreversibly with a liquid phase component $\mathrm{B}$. We used the reaction between $\mathrm{CO}_{2}$ and diethanolamine (DEA). The reaction order with respect to $\mathrm{CO}_{2}$ is unity whereas, with respect to DEA, the order is between one and two, depending on concentration, see Versteeg and Van Swaaij [3]. Provided that $2<\mathrm{Ha} \leq 10 E_{\mathrm{CO}, \infty}$, all the absorbed $\mathrm{CO}_{2}$ reacts near the interface and there is no limitation on the amine 
transport from the liquid bulk to the interface. The Hatta number Ha can be adjusted by choosing the type of amine and its concentration as well as the maximum enhancement factor $E_{\mathrm{CO}, \infty}$ by the concentration of carbon dioxide in the gas phase. If gas phase mass transfer resistance exerts no influence, the absorption flux is described by ${ }^{1)}$ (see Westerterp et al. [4]).

$J_{\mathrm{CO} 2}=m c_{\mathrm{CO} 2, \mathrm{~g}} \sqrt{k_{1, \mathrm{p}} c_{\mathrm{DEA}, 1}^{p} D_{\mathrm{CO} 2,1}}$.

The gas phase in a trickle-flow reactor can be assumed to be in plug flow and of constant density and velocity. Thus, the mass balance for carbon dioxide about a differential volume element becomes

$v_{\mathrm{g}} \frac{\mathrm{d} c_{\mathrm{CO} 2, \mathrm{~g}}}{\mathrm{~d} x}=-J_{\mathrm{CO} 2} a_{\mathrm{gl}}$.

Substitution of Eq. (1) into Eq. (2) and integration of Eq. (2) over the reactor length, under the condition of a constant Hatta number, results in the following relationship between the gasliquid interfacial area per unit volume $a_{\mathrm{gl}}$ and the overall gas phase conversion $\xi$ of carbon dioxide

$a_{\mathrm{gl}}=\left(\frac{-v_{\mathrm{g}}}{m L \sqrt{k_{1, \mathrm{p}} c_{\mathrm{DEA}, 1}^{p} D_{\mathrm{CO} 2,1}}}\right) \ln \left(1-\xi_{\mathrm{CO} 2}\right)$

In our experiments, the amine conversion was always less than $12 \%$, so that the Hatta number remained approximately constant. The interfacial areas were reproducible with an accuracy of $15 \%$. The physical properties and kinetic data of the systems at $298 \mathrm{~K}$, as used in this study, were taken from Oyevaar et al. $[5-7]$ and are listed in Table 1. A small amount of an antifoam agent was added to the aqueous $2 \mathrm{M}$ DEA-solution.

Fig. 1 shows a simplified flow diagram of the installation. The trickle-bed reactor, which had an inner diameter of $51 \mathrm{~mm}$, was maintained at $298 \mathrm{~K}$. The packed bed was $0.53 \mathrm{~m}$ high and had overall porosities of 0.43 and 0.39 for the cylindrical and the spherical packings, respectively. The maximum superficial gas and liquid velocities, based on the empty reactor cross-section, were $0.25 \mathrm{~m} / \mathrm{s}$ and $12 \mathrm{~mm} / \mathrm{s}$, respectively. To reduce gas consumption, the gas phase was recycled in the installation and a mixture of carbon dioxide in nitrogen was added continuously and mixed with the recycle gas. Near the reactor inlet and just

Table 1. Physical and kinetic properties of fluids used in absorption experiments at $298 \mathrm{~K}$

\begin{tabular}{|c|c|c|c|}
\hline & & $\begin{array}{l}\text { Aqueous } \\
2 \mathrm{M} \text { DEA }\end{array}$ & $\begin{array}{l}\text { 1.5M DEA in } \\
40 \% \text { ETG-water }\end{array}$ \\
\hline$m\left(k_{\mathrm{l}, \mathrm{p}}\left({ }^{\prime \prime}{ }_{\mathrm{D}) \mathrm{LA,1}} D_{(\mathrm{O}, \mathrm{l}, 1}\right)^{1 / 2}\right.$ & {$[\mathrm{m} / \mathrm{s}]$} & $9.5 \times 10^{-4}$ & $5.0 \times 10^{-4}$ \\
\hline$m$ & $1-1$ & 0.70 & 0.65 \\
\hline$e_{1}$ & $\left\{\mathrm{~kg} / \mathrm{m}^{3}\right\}$ & 1022 & 1060 \\
\hline$\eta_{1}$ & {$\left[\mathrm{Ns} / \mathrm{m}^{2}\right]$} & $1.7 \times 10^{-3}$ & $4.0 \times 10^{-3}$ \\
\hline$D_{\mathrm{CO} 2,1}$ & {$\left[\mathrm{~m}^{2} / \mathrm{s}\right]$} & $1.0 \times 10^{-9}$ & $0.7 \times 10^{-9}$ \\
\hline$D_{\text {DFA,I }}$ & {$\left[\mathrm{m}^{2} / \mathrm{s}\right]$} & $0.5 \times 10^{-9}$ & $0.26 \times 10^{-9}$ \\
\hline
\end{tabular}

1) List of symbols at the end of the paper. below the packing at the bottom of the column, the gas phase was sampled continuously in order to measure the carbon dioxide content. A backpressure regulator maintained the pressure in the plant at the desired value.

\subsection{Flow-regime Transition, Liquid Hold-up and Pressure Drop}

The experimental set-up, used for the determination of the flow regime transition, the total external liquid hold-up and the pressure drop, is basically the same as that shown in Fig. 1. The height of the packed bed is $2.70 \mathrm{~m}$. A section of the tube wall, $1 \mathrm{~m}$ long, has been manufactured from polycarbonate material, so as to enable us to observe visually the flow pattern at high pressures. The maximum superficial gas and liquid velocities applied were $0.36 \mathrm{~m} / \mathrm{s}$ and $16 \mathrm{~mm} / \mathrm{s}$, respectively. Physical properties of the fluids used in this study are listed in Table 2 .

The draining method was used to determine the total external liquid hold-up. The total hold-up is the sum of the dynamic hold-up, which drains from the column, and the residual holdup remaining inside the packed bed. The residual hold-up is independent of gas and liquid flow, see Shulman et al. [8], and we assumed that it is also independent of reactor pressure. Data of the dynamic and residual hold-ups are reproducible within a relative error of 5 and $10 \%$, respectively.

The pressure drop over the bed was determined via a differential pressure transmitter with the high pressure end connected to reactor wall at $20 \mathrm{~cm}$ below the top of the bed, in order to avoid entrance effects.

The transition between trickle and pulse flow was observed visually in the transparent middle section of the column.

Gas density and velocity values are based on entrance conditions because the pressure gradients are small in comparison to the average absolute reactor pressure.

\section{Results}

\subsection{Flow-regime Transition}

Several flow patterns can be observed in the cocurrent gas-liquid trickle-bed reactor. They are generally classified as trickle, pulse, spray and dispersed-bubble flow, see for example Gianetto et al. [9]. Normally, only trickle flow and pulseflow regimes are encountered in industrial trickle-flow columns. In the former case, the liquid trickles over the packing as a thin film and the gas phase flows downward through the voids. In the pulse-flow regime, the liquid periodically blocks the channels between the packing particles. Above the liquid plug, local pressure increases rapidly until the plug is blown downward through the column at a relatively high velocity. Information on the operating conditions, at which the transition occurs, is essential for design calculations because pressure drop, liquid hold-up and especially the gas-liquid interfacial area are differently affected in each regime. 


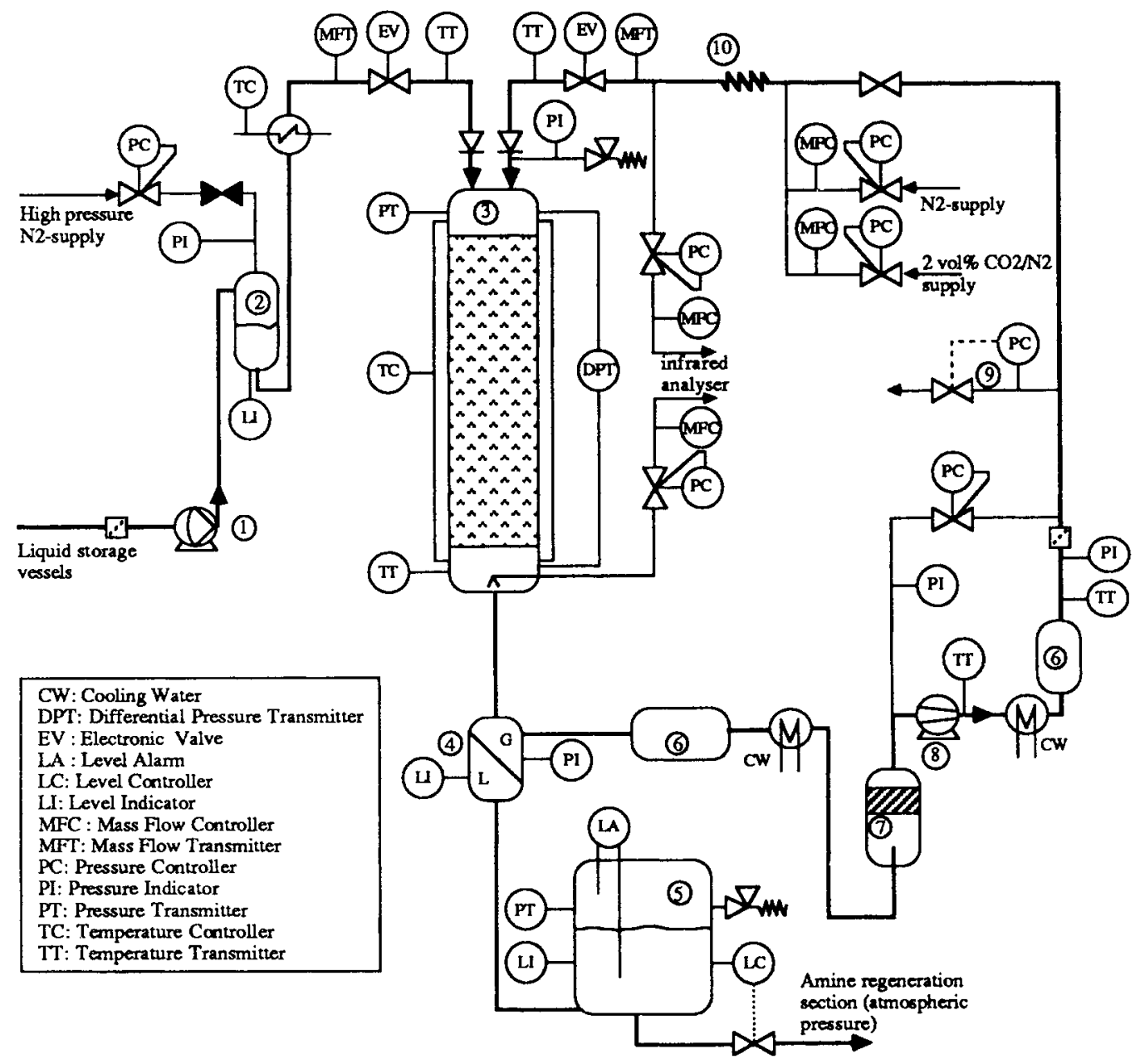

Fig. 1. Simplified flow diagram; 1 liquid pump, 2 air-chamber $/ \mathrm{N}_{2}$-saturation, 3 trickle-bed reactor, 4 gas-liquid separator, 5 level-controlled buffer vessel, 6 gas buffers, 7 demister, 8 gas compressor, 9 backpressure valve, 10 gas mixer.

Table 2. Physical properties of fluids used in flow-regime transition, liquid hold-up and pressure drop experiments, at $293 \mathrm{~K}$.

\begin{tabular}{llll}
\hline & $\varrho\left[\mathrm{kg} / \mathrm{m}^{3}\right]$ & $10^{3} \sigma_{\mathrm{lg}}[\mathrm{N} / \mathrm{m}]$ & $10^{3} \eta\left[\mathrm{N} \mathrm{s} / \mathrm{m}^{2}\right]$ \\
Water & 1000 & 72 & 1.0 \\
$40 \%$ ethylene glycol & 1050 & 60 & 2.9 \\
Ethanol & 790 & 22 & 1.2 \\
Nitrogen & $1.15 \times P_{\mathrm{r}}$ & & 0.017 at $1 \mathrm{bar}$ \\
& & & 0.019 at $100 \mathrm{bar}$ \\
Helium & $0.16 \times P_{\mathrm{r}}$ & 0.019 at $1 \mathrm{bar}$ \\
& & & 0.020 at $100 \mathrm{bar}$
\end{tabular}

It is known from literature, see for example Sai and Varma [10], that the flow-regime boundary depends on the superficial gas and liquid velocities, the physical properties of liquid phase and on particle size, geometry and surface properties. Fig. 2 presents the transition between trickle and pulse flow, as determined for water and $3 \mathrm{~mm}$ glass spheres, as a function of superficial gas and liquid velocities, at several gas densities. It is seen that the gas density exerts a strong influence on the gas and liquid velocities at which the transition takes place. At higher gas densities, the transition line shifts towards higher liquid throughputs and the operating region for trickle flow thereby becomes larger. In the gas density range between 28 and 86 $\mathrm{kg} / \mathrm{m}^{3}$, the pulse-flow regime could no longer be observed. It is also shown that the transition conditions obtained for helium at 7.0 MPa and nitrogen at 1.0 MPa, for which the gas densities are equal since $M_{\mathrm{N} 2} / M_{\mathrm{He}}=7$, are the same. This demonstrates that, for a given liquid-solid system at equal gas densities, the

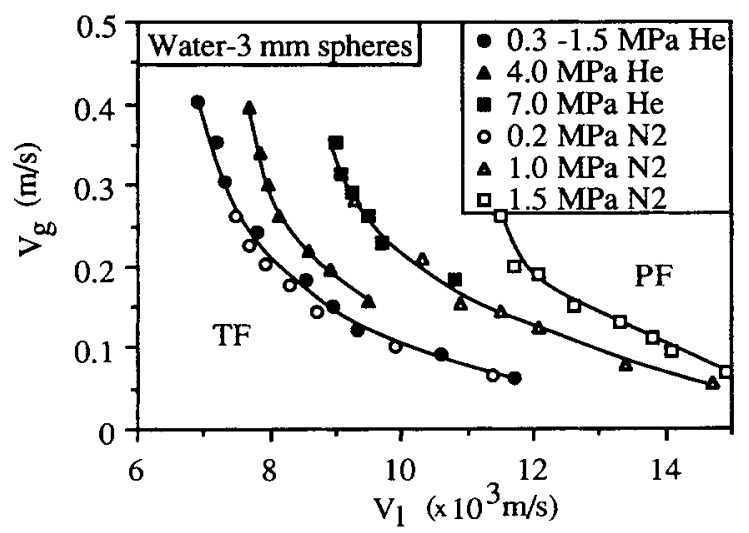

Fig. 2. Transition between trickle flow (TF) and pulse flow (PF) as a function of superficial gas and liquid velocities, with gas density as parameter. 
hydrodynamic states are the same. Similar results are obtained with ethanol and aqueous $40 \%$ ethylene glycol. Furthermore, at a given gas density, the gas and liquid velocities, at which transitions take place, depend on the type of liquid and packing particles, see Wammes et al. [11], just as reported in literature for atmospheric conditions.

Fig. 3 presents the total external liquid hold-up at flow-regime transition $\beta_{\mathrm{t}, \mathrm{tr}}$ for the system aqueous $40 \%$ ethylene glycol and $3 \mathrm{~mm}$ glass spheres, plotted against the superficial gas velocity for different gas densities. The mean thickness of the liquid film on the packing particles is proportional to the total external liquid hold-up. The diagram shows that the minimum liquid hold-up or film thickness at which the pulses are initiated, is slightly lower at higher gas densities. This decrease is roughly proportional to $\varrho_{g}^{-0.05}$. Comparable results for the relationship between total hold-up $\beta_{\mathrm{t}, \mathrm{tr}}$ and gas density were obtained for the other liquids tested. However, the magnitude of $\beta_{\mathrm{t}, \mathrm{tr}}$ depends on the liquid phase properties, e.g., in the case of ethanol, pulses are initiated at lower hold-ups than for aqueous $40 \%$ ethylene glycol.

The displacement of the transition line towards higher liquid throughputs, see Fig. 2, can be explained as follows. If the reactor operates in the pulse-flow regime near the transition and the gas density is increased, the pressure gradient increases leading to a decrease of liquid hold-up (see also sections 3.3 and 3.4). The hold-up becomes less than the minimum value at which liquid films collapse in the interstices between the particles and block the gas flow. Hence, the flow regime changes from pulse to trickle flow. In order to operate the reactor in the pulse-flow regime again, at an enhanced gas density, the film thickness or hold-up must be enlarged by increasing the liquid throughput.

Wammes et al. [1] examined the applicability of the various flow charts and model equations, as reported in literature, to the results of flow-regime transitions at enhanced gas densities. None of these models gives a good prediction of the density influence as observed in this study. For water, only the flow diagram of Talmor [12] predicts the transition at elevated pressures reasonably well. A quantitative description of the

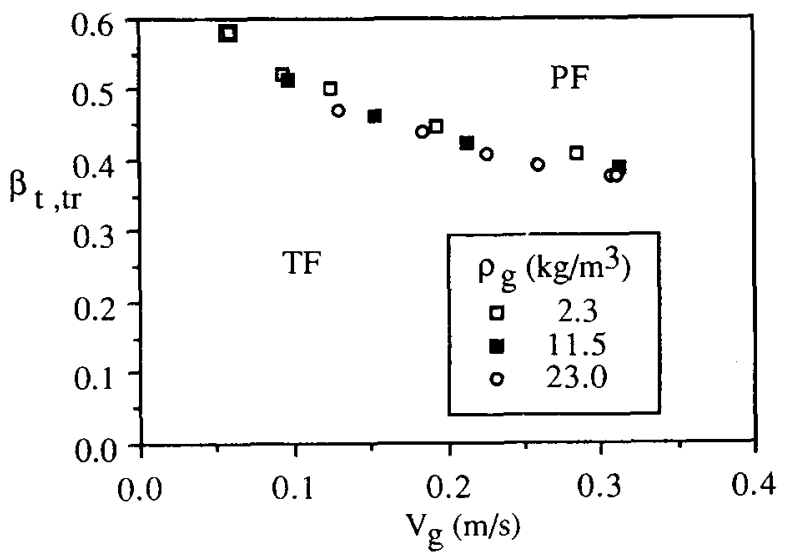

Fig. 3. Total external liquid hold-up at transition between trickle and pulse flow for aqueous $40 \%$ ETG and $3 \mathrm{~mm}$ glass spheres. transition between trickle and pulse flow as a function of operating conditions, physical properties of the fluids and properties of the packing is not yet available. However, for a given liquid-solid system, the total liquid hold-up at flow-regime transition at elevated pressures, see Fig. 3, can be extrapolated from atmospheric experiments or determined at atmospheric pressure by using a gas of a large molar mass. Then, the liquid hold-up has to be determined experimentally at the desired operating conditions. By comparing this hold-up with the minimum hold-up at which pulse flow starts, it can be predicted whether the reactor will operate under trickle or pulse-flow conditions.

\subsection{Gas-liquid Interfacial Area in the Trickle-flow Regime}

To determine the overall conversion rate in the case of relatively fast chemical reactions, the gas-liquid mass transfer rate has to be evaluated. This rate is determined by the liquid phase mass transfer coefficient $k_{1}$ and the interfacial area per unit volume $a_{\mathrm{gl}}$. The change in $k_{1} a_{\mathrm{gl}}$ as a function of the gas flow rate is mainly due to changes in the gas-liquid contact area, see for example Hirose et al. [13]. Literature data indicate that $k_{1}$ increases with the $0.3-0.4$ th power of interstitial liquid velocity.

The interstitial velocity is given by:

$u_{1}=\frac{v_{1}}{\varepsilon \beta_{\mathrm{dyn}}}$.

At an increased gas density and a constant superficial liquid velocity, the mean interstitial velocity becomes higher because the hold-up decreases as will be shown in section 3.4. The $k_{1}$ values determined at atmospheric pressure, and normally correlated to $v_{1}$, can be extrapolated to higher pressures by correcting for the influence of the change in liquid velocity $u_{1}$.

The effect of gas density on gas-liquid interfacial area $a_{\mathrm{gl}}$ is more difficult to predict on the basis of literature data because the interaction between gas and liquid in the packed bed is very complex. Therefore, experiments were performed to obtain qualitative information on the gas density effect. The gas-liquid interfacial area as well as the pressure drop, determined for the system of aqueous $2 \mathrm{M}$ DEA and $3 \mathrm{~mm}$ glass spheres, exhibited hysteresis. If liquid throughput is adjusted, starting from a relatively high value, the pressure drop and the contact area are larger than when the throughput is increased from a low value. Hysteresis is probably the result of poor wetting conditions on the solid surface, see Levec et al. [14] and Wammes et al. [2]. No hysteresis was observed for the viscous amine solution, either in the flow-regime transition, or the liquid hold-up and pressure drop experiments performed with the other gas-liquid-solid systems.

The reduced interfacial areas $a_{\mathrm{gl}} / a_{\mathrm{s}}$ for two amine solutions of different viscosities are approximately the same at equal superficial gas and liquid velocities and pressure. However, if a variation in liquid phase properties leads to a change in the flow behaviour, the contact area can alter considerably, see Morsi et al. [15]. 
Fig. 4 presents the reduced interfacial area of the viscous amine solution, plotted as a function of the superficial gas velocity at different liquid throughputs. It shows that the contact area increases with the superficial gas velocity, whereas the influence of the superficial liquid velocity is relatively small. A typical example of the gas density effect on reduced interfacial area is shown in Fig. 5. At enhanced gas densities, the gas-liquid contact area increases, its influence being smaller than that of the gas velocity. On the basis of the penetration theory, it has been estimated, see Wammes et al. [2], that, in the absorption experiments, the resistance of the $\mathrm{CO}_{2}$ transport in the gas phase can no longer be neglected at gas densities in excess of 18 and $70 \mathrm{~kg} / \mathrm{m}^{3}$ for aqueous and viscous DEA-solutions respectively. Under these conditions, it is not possible to determine the interfacial area from absorption experiments because of lack of data on $k_{\mathrm{g}}$ for trickle flow. For high pressure operations with hydrogen or oxygen as reactants, the influence of the gas side mass transfer resistance will mostly be negligible because the solubilities of these gases are much lower than that of carbon dioxide.

Within the range of our operating conditions, the gas-liquid contact areas of both amine solutions are between 25 and $80 \%$ of the geometric packing area. According to literature, see for example Hirose et al. [13], after transition from trickle to pulse flow, the contact area increases markedly and can even by far exceed the geometric packing area, due to the extra contribution of small gas bubbles inside the pulses. From the values of contact areas and the fact that $a_{\mathrm{gl}} / a_{\mathrm{s}}$ is not very much affected by $v_{g}, v_{1}$ and $e_{g}$, we conclude that, under any conditions, the reactor operated in the trickle-flow regime. In the preceding section, we concluded that enhanced gas density increases the operating region for trickle flow. The finding that no large increase in the gas-liquid interfacial area has been observed with increasing gas density, supports the conclusion that no transition to pulse flow had occurred.

A qualitative explanation of the increase in $a_{\mathrm{gl}} / a_{\mathrm{s}}$ as being the result of increased gas velocity or density, can be found in the simultaneously decreased average liquid film thickness, which is proportional to the liquid hold-up. The geometric packing

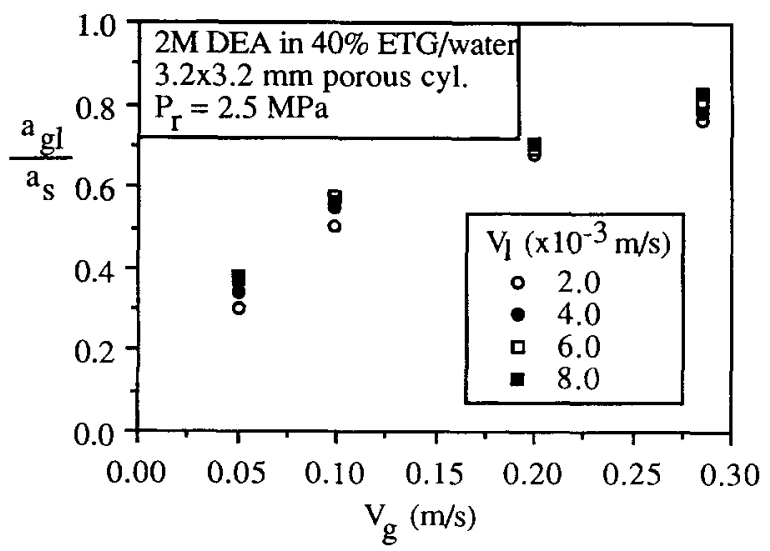

Fig. 4. Influence of superficial gas velocity at different superficial liquid velocities on reduced interfacial area of the viscous amine system at 2.5 MPa.

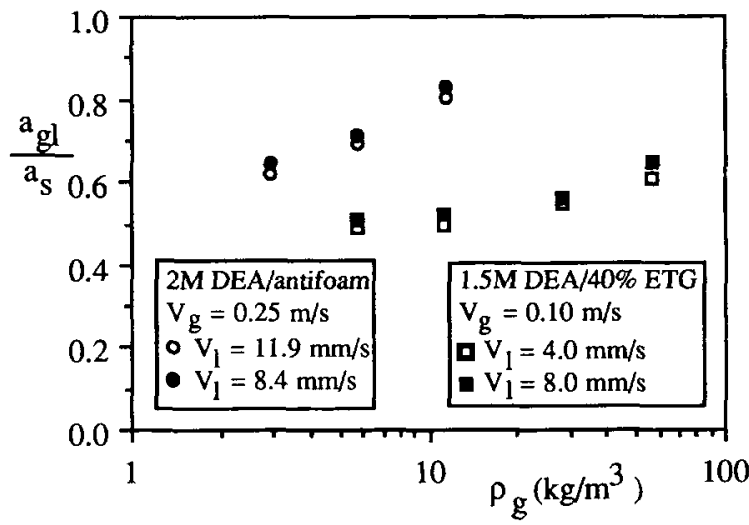

Fig. 5. Influence of gas density at different superficial liquid velocities on reduced interfacial area

area is used more effectively in creating gas-liquid contact area when the flowing liquid film is thinner. Moreover, due to the higher shear stress at the interface, the contact area becomes more rippled. The observation that the contact area remains practically constant on increasing liquid throughput, despite the increasing average liquid film thickness, may be due to two opposing phenomena. On the one hand, the thicker liquid film is less capable of following the shape of the packing particles. On the other hand, a thicker liquid film can exhibit larger ripples at the gas-liquid interface.

\subsection{Pressure Drop in the Trickle-flow Regime}

The results of the pressure drop experiments without liquid flow in a dry and a prewetted bed can be well described by the Ergun equation. Only the two constants in the equation were different for both conditions, presumably because the geometry of the friction area differs for a dry and for a prewetted bed. In the case of gas-liquid flow, it has been found that the pressure drop increases at higher superficial liquid and gas velocities and also with the density of the gas phase as shown in Fig. 6. A commonly used approach to take the effect of liquid flow on pressure drop into account is to correct the bed porosity term $\varepsilon$ in the Ergun equation for the presence of the

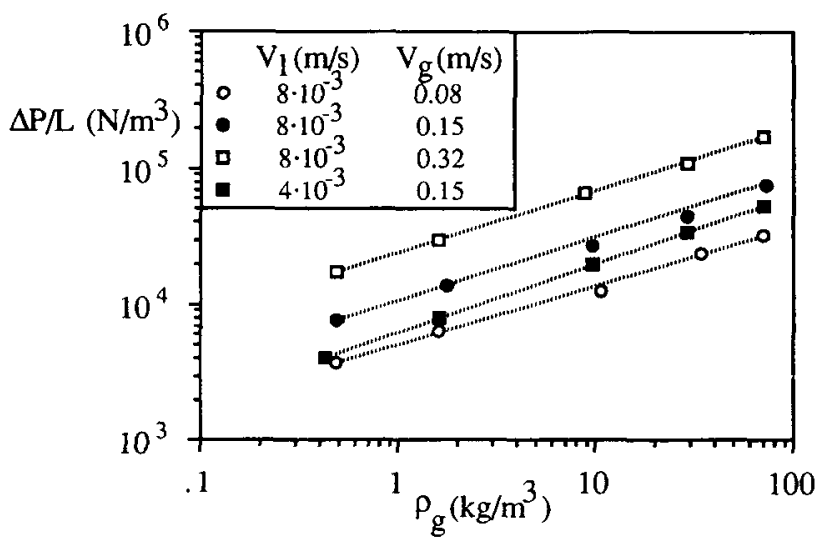

Fig. 6. Influence of gas density at different superficial gas and liquid velocities on pressure gradient for the system ethanol $-3 \mathrm{~mm}$ glass spheres. 
liquid hold-up $\beta_{1}$, so that $\varepsilon^{*}=\varepsilon\left(1-\beta_{1}\right)$, see for example Specchia and Baldi [16]. Unfortunately, we found that, at approximately $\varrho_{g} v_{\varepsilon} /\left(1-\varepsilon^{*}\right)>15$, the modified equation starts to overestimate the pressure gradient. Therefore, we used another approach starting from the forces balance for the gas phase. In Wammes et al. [11], we derived the following expression for the pressure gradient

$\frac{\Delta P}{L}=f_{\mathrm{lg}} \frac{1}{2} \varrho_{\mathrm{g}} u_{\mathrm{g}}^{2} \frac{1-\varepsilon}{d_{\mathrm{p}} \varepsilon\left(1-\beta_{\mathrm{t}}\right)}$,

with $u_{\mathrm{g}}$ representing the mean interstitial gas velocity calculated as

$u_{\mathrm{g}}=\frac{v_{\mathrm{g}}}{\varepsilon\left(1-\beta_{\mathrm{t}}\right)}$.

The dimensionless two-phase friction factor $f_{\mathrm{lg}}$ is an empirical term which lumps all the unknown phenomena occurring at the gas-liquid interface and has to be determined experimentally. For $\beta_{\mathrm{t}}>0.25$ and $200<\operatorname{Re}_{\mathrm{g}}<5000$, with the Reynolds number based on $u_{\mathrm{g}}$ and on the hydraulic diameter for a dry packing $\varepsilon / a_{\mathrm{s}}$ since $a_{\mathrm{gl}}$ is unknown, we established by parameter optimization that $f_{\mathrm{lg}}$ is independent of the liquid velocity and can be described by

$f_{\mathrm{lg}}=\operatorname{Re}_{\mathrm{g}}^{-0.37}$

This results in the following dimensionless pressure drop correlation

$\frac{\Delta P}{1 / 2 \varrho_{\mathrm{g}} u_{\mathrm{g}}^{2}}\left(\frac{d_{\mathrm{p}}}{L}\right)=155\left(\frac{\varrho_{\mathrm{g}} u_{\mathrm{g}} \varepsilon d_{\mathrm{p}}}{\eta_{\mathrm{g}}(1-\varepsilon)}\right)^{-0.37}\left(\frac{1-\varepsilon}{\varepsilon\left(1-\beta_{\mathrm{t}}\right)}\right)$.

The mean relative error in the prediction is $12 \%$ and its standard deviation is 0.14 . The influence of the liquid flow rate is taken into account by the liquid hold-up. At values of $\beta_{t}<$ 0.25 , and hence $\beta_{\text {dyn }}<0.13$, the correlation underestimates the pressure gradient. This also follows from the fact that, in the limiting cases of a dry bed $\beta_{\mathrm{t}}=0$ and a prewetted bed $\beta_{\mathrm{t}}$ $=\beta_{\mathrm{I}}$, the pressure gradient is well described by the Ergun equation, in which $\Delta P / L$ is proportional to $\varrho_{\mathrm{g}} v_{\mathrm{g}}{ }^{2}$ for $\mathrm{Re}_{\mathrm{g}}>$ 1500 , in contrast to the description given by Eq. (8). The findings for $\beta_{t}>0.25$ show more resemblance to gas flow in straight channels for which, at $\mathrm{Re}_{\mathrm{g}}=\varrho_{\mathrm{g}} u_{\mathrm{g}} R_{\mathrm{h}} / \eta_{\mathrm{g}}<500$, the friction factor is proportional to $\operatorname{Re}_{\mathrm{g}}^{-1}$ and, for $500<\mathrm{Re}_{\mathrm{g}}$ $<25 \times 10^{3}$, proportional to $\operatorname{Re}_{g}{ }^{-0.25}$. This is also supported by the pressure drop correlation for trickle-flow operation, given by Rao et al. [17], in which the pressure drop is approximately proportional to $\varrho_{\mathrm{g}}^{0} v_{\mathrm{g}}^{1}$ up to $\mathrm{Re}_{\mathrm{g}} \approx 200$ and hence $\mathrm{f}_{\mathrm{lg}}$ is proportional to $\mathrm{Re}_{\mathrm{g}}^{-1}$.

\subsection{Total External Liquid Hold-up in the Trickle-flow Regime}

The total external liquid hold-up, i.e. the liquid hold-up in the free volume between the catalyst particles, is an important design parameter. The mean liquid phase residence time, wetting of the external catalyst surface and, as previously shown, the pressure drop across the bed are related to it. Using the draining method, the hold-up is resolved into a residual part, located around the particle contact points, and a dynamic part trickling out of the column. Under reactor operation, the liquid hold-up around the particle contact points is not completely stagnant but the transport rate of the species to and from the catalyst particle through this zone is relatively low. Hence, the effective catalyst area for mass transfer is apparently smaller than the geometric surface area. The residual liquid hold-up can be used as a first estimate of the loss in effective external catalyst surface area and thus of the loss in catalyst effectiveness.

\subsubsection{Residual Liquid Hold-up}

The liquid remaining inside the bed around the contact points of the particles after draining is the result of the balance between capillary and gravity forces. Van Swaaij [18] proposed a relationship between this hold-up and the Eötvös number, Eö $=e_{1} g d_{\mathrm{p}}^{2} / \sigma_{\mathrm{lg}}$, which is applicable to well wettable packing particles. The residual liquid hold-up data, obtained for the liquidsolid systems as used in this study, all result in $\varepsilon \beta_{\mathrm{r}}=0.06$ as predicted by the relationship, except for the system aqueous DEA-solution and $3 \mathrm{~mm}$ glass spheres with a small amount of antifoam agent, where we found $\varepsilon \beta_{\mathrm{r}} \approx 0.03$. This is probably due to poor wetting of the glass surface because the antifoam agent was adhering to the glass particles.

\subsubsection{Dynamic Liquid Hold-up}

It is known from literature that the dynamic liquid hold-up depends on several variables: the superficial gas and liquid velocities, physical properties of the liquid phase and properties of the packed bed and packing material. In Fig. 7, the dynamic liquid hold-up has been plotted as a function of the superficial liquid velocity at various superficial gas velocities and gas densities. Without gas flow, the liquid hold-up is independent of the gas density. At low gas densities, this hold-up is hardly affected by the gas flow. At relatively higher gas densities, the gas flow reduces the hold-up considerably. On the basis of force balances around the liquid and the gas phase, see Wam-

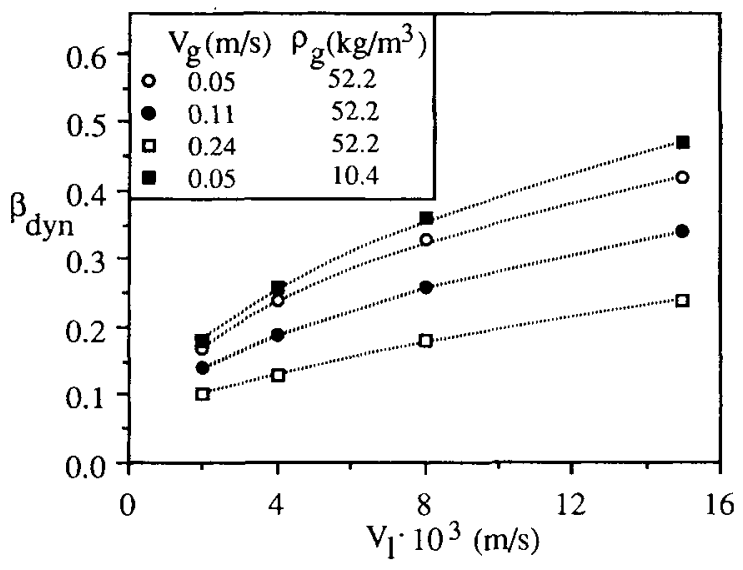

Fig. 7. Influence of superficial liquid velocity at different superficial gas velocities and densities on dynamic liquid hold-up for the system water $3.2 \times 3.2 \mathrm{~mm}$ ceramic cylinders. 
mes et al. [11], it can be shown that these phenomena can be explained by means of the pressure gradient in relation to the gravity force, the two driving forces both acting on the liquid phase. The gravity force $\varrho_{1} g$ is constant, whereas the pressure gradient $\Delta P / L$ depends on gas density and gas velocity. Without gas flow, the ratio $\Delta P / \varrho_{1} g L$ is zero because $\Delta P=0$. At small ratios $\Delta P / \varrho_{1} g L<0.1$, which is the case at low $\varrho_{\mathrm{g}}$ and $v_{\mathrm{g}}$-values, the relative contribution of the pressure drop to the total driving force is negligible and therefore the hold-up is practically unaffected by the gas flow rate. However, at higher pressure drops, say $\Delta P / \varrho_{1} g L>0.25$, the hold-up decreases markedly due to an increase in $\varrho_{\mathrm{g}}$ and/or $v_{\mathrm{g}}$. For the mathematical description of the dynamic liquid hold-up, good results have been obtained by using a power product of dimensionless numbers, i.e. a liquid phase Reynolds number, a Galileo number modified by $1+\Delta P / \varrho_{1} g L$ and a number containing properties of the bed, see Specchia and Baldi [16]. The influence of the gas flow rate is implicitly completely taken care of by its influence on $\Delta P$, see Eq. (8). The gas-liquid surface tension did not influence the dynamic hold-up. On the basis of 220 hold-up experiments in the trickle-flow regime, the following correlation has been derived:

$\beta_{\mathrm{dyn}}=3.8\left(\frac{\varrho_{1} v_{1} d_{\mathrm{p}}}{\eta_{\mathrm{1}}}\right)^{0.55}\left(\frac{d_{\mathrm{p}}^{3} \varrho_{1}^{2} g}{\eta_{1}^{2}}\left(1+\frac{\Delta P}{\varrho_{1} g L}\right)\right)^{-0.42}\left(\frac{a_{\mathrm{s}} d_{\mathrm{p}}}{\varepsilon}\right)^{0.65}$

The dimensionless groups ranged between $2 \leq \mathrm{Re}_{1} \leq 55$, $3.2 \times 10^{3} \leq \mathrm{Ga}_{1} \leq 0.32 \times 10^{6}$ and $0 \leq \Delta P / \varrho_{1} g L \leq 16$. The mean relative error is $8 \%$ and its standard deviation 0.1 . The cases of negligible gas flow effect and of no gravity influence are both well described by this correlation. Only in the case without gas flow and over the range of $\mathrm{Re}_{1}$ decreasing from 15 to 11 , the exponent on the Reynolds number changes from 0.55 to 0.36 , see Wammes et al. [19].

\section{Discussion and Conclusions}

Studies on the hydrodynamic behaviour of the cocurrent gas-liquid trickle-bed reactor have mostly been performed under atmospheric conditions, whereas in the industrial practice these reactors operate at elevated pressures. In this study, several hydrodynamic aspects have been investigated at pressures of up to $7.5 \mathrm{MPa}$ with nitrogen or helium as the gas phase and with various liquids. The hydrodynamic behaviour depends on the gas density and not on the gas pressure.

Under gas-liquid trickle-flow conditions, hysteresis behaviour can occur and this is probably due to imperfect wetting of the particle surface.

At high gas densities, the transition between trickle-flow and pulse-flow regimes takes place at higher liquid throughputs and therefore the operating region for trickle flow becomes larger. A prediction of the flow-regime transition on the basis of physical properties of the three-phase system and the operating conditions is at present not yet possible because the mechanisms governing the pulse initiation are not well understood.
Under trickle-flow conditions, the gas-liquid interfacial area increases only slightly at higher gas densities. As a first approximation, results on the contact area determined at atmospheric pressure can be used at higher densities, except when, due to the density increase, a transition from pulse to trickle flow takes place.

The total external liquid hold-up has been resolved into a residual and a dynamic part. The residual hold-ups for systems with good liquid-solid contacting are well described as a function of the Eötvös number as proposed by Van Swaaij [18]. According to this relationship, the residual hold-up of packed beds, as usually encountered in catalytic trickle-flow processes, will be about $\varepsilon \beta_{\mathrm{r}} \approx 0.06$. For the dynamic liquid hold-up, a dimensionless correlation, Eq. (9), has been put forward, containing the pressure drop. Moreover, a dimensionless correlation for the pressure drop, Eq. (8), has been derived, containing the liquid hold-up. By means of Eqs (6), (8) and (9) and the residual hold-up value, the total external liquid hold-up and pressure drop under trickle-flow conditions can be determined.

At the transition to pulse flow, no sudden changes in the holdup or pressure drop have been observed. The presented correlations are also capable of describing both parameters at the flowregime transition but, under stronger pulse-flow conditions, the liquid hold-up will be overestimated whereas the pressure drop will be underestimated.

It is known that, in large-scale columns, a homogeneous distribution of the phases is difficult to obtain. The local gas and liquid velocities may vary considerably, leading to coexistence of local trickle and pulse flows. In our laboratory-scale column, this did not occur. On the basis of the present work, it can be concluded that, in most cases, the commercial high pressure trickle-flow reactors operate in the trickle-flow regime, because the relatively high liquid throughputs required to generate pulse flow are outside the normally applied range. In our installation, the number of particles on the column diameter is sufficiently large for the wall effects to be negligible. Thus, we would like to express our confidence in the possibility of extrapolating our results and correlations to columns with much larger diameters.

Received: October 31, 1990 [CET 340]

\section{Symbols used}

\begin{tabular}{|c|c|c|}
\hline$a$ & {$\left[\mathrm{~m}^{2} \mathrm{~m}^{3}\right]$} & interfacial area per unit volume \\
\hline$c$ & {$\left[\mathrm{~mol} / \mathrm{m}^{3}\right]$} & concentration \\
\hline$d_{\mathrm{p}}$ & {$[\mathrm{m}]$} & nominal particle diameter \\
\hline$D$ & {$\left[\mathrm{~m}^{2} / \mathrm{s}\right]$} & diffusion coefficient \\
\hline$E_{\infty}$ & & $\begin{array}{l}\text { maximum possible enhancement factor: } \\
\left(D_{\mathrm{CO} 2,1} / D_{\mathrm{DEA}, 1}\right)^{1 / 2}+\left\{\left(D_{\mathrm{DEA}, 1} / D_{\mathrm{CO}, 1}\right)^{1 / 2} \times\right. \\
\left.\times c_{\mathrm{DEA}, 1} /\left(2 m c_{\mathrm{CO}, 1}\right)\right\}\end{array}$ \\
\hline Eö & & Eötvös number $\varrho_{1} g d_{\mathrm{p}}^{2} / \sigma_{\mathrm{gl}}$ \\
\hline$f$ & & friction factor \\
\hline$g$ & {$\left[\mathrm{~m} / \mathrm{s}^{2}\right]$} & gravitational acceleration \\
\hline $\mathrm{Ga}_{1}$ & & liquid phase Galileo number $d_{\mathrm{p}}^{3} \varrho_{1}^{2} g / \eta_{1}^{2}$ \\
\hline HA & & Hatta number $\left(k_{1, \mathrm{p}} c_{\mathrm{DEA}, 1} p D_{\mathrm{CO} 2,1}\right)^{1 / 2} / k_{1}$ \\
\hline$J$ & {$\left[\mathrm{~mol} /\left(\mathrm{m}^{2} \mathrm{~s}\right)\right]$} & mass transfer flux \\
\hline
\end{tabular}


$k \quad[\mathrm{~m} / \mathrm{s}] \quad$ mass transfer coefficient

$k_{1, \mathrm{p}} \quad\left[\mathrm{m}^{3 p} / \mathrm{mol}^{p} \mathrm{~s}\right]$ reaction rate constant for a $(1, p)$-order of reaction

$L \quad[\mathrm{~m}] \quad$ packing height

$m \quad$ distribution coefficient $\left(c_{\mathrm{i}, \mathrm{l}} / c_{\mathrm{i}, \mathrm{g}}\right)_{\mathrm{eq}}$

$M \quad[\mathrm{~kg} / \mathrm{mol}] \quad$ molar mass

$p \quad$ order of reaction with respect to amine

$\begin{array}{lll}P_{\mathrm{r}} & {[\mathrm{bar}]} & \text { absolute pressure at reactor inlet }\end{array}$

$\Delta P \quad\left[\mathrm{~N} / \mathrm{m}^{2}\right] \quad$ pressure difference

$\mathrm{Re}_{\mathrm{g}} \quad$ gas phase Reynolds number $\varrho_{\mathrm{g}} u_{\mathrm{g}} R_{\mathrm{h}} / \eta_{\mathrm{g}}$

$\mathrm{Re}_{1} \quad$ liquid phase Reynolds number $\varrho_{1} v_{1} d_{\mathrm{p}} / \eta_{1}$

$R_{\mathrm{h}} \quad[\mathrm{m}] \quad$ hydraulic diameter

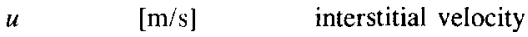

$v \quad[\mathrm{~m} / \mathrm{s}] \quad$ superficial velocity, based on cross-sectional

area of empty reactor

[m] axial length coordinate

\section{Greek symbols}

$\begin{array}{lll}\beta & {\left[\mathrm{m}^{3} / \mathrm{m}^{3}\right]} & \begin{array}{l}\text { liquid hold-up based on void volume } \\ \text { porosity of packed bed } \\ \text { modified porosity } \varepsilon\left(1-\beta_{\mathrm{t}}\right)\end{array} \\ \varepsilon^{*} & & \begin{array}{l}\text { viscosity } \\ \text { density }\end{array} \\ \eta & {\left[\mathrm{Ns} / \mathrm{m}^{2}\right]} & \text { gas-liquid surface tension } \\ \varrho & {\left[\mathrm{kg} / \mathrm{m}^{3}\right]} & \text { conversion }\end{array}$

\section{Indices}

$\begin{array}{ll}\text { dyn } & \text { dynamic } \\ \mathrm{g} & \text { gas phase } \\ \mathrm{I} & \text { liquid phase } \\ \mathrm{r} & \text { residual } \\ \mathrm{s} & \text { solid phase } \\ \mathrm{t} & \text { total }\end{array}$

\section{References}

[1] Wammes, W.J.A., Mechielsen, S.J., Westerterp, K.R., Chem. Eng Sci. 45 (1990a) pp. 3149-3158.

[2] Wammes, W.J.A., Huisman, W.J., de Baas, C.M., Westerterp, K.R., submitted to $A I C h E J$.

[3] Versteeg, G.F., Van Swaaij, W.P.M., Chem. Eng Sci. 43 (1988) pp. $573-585$.

[4] Westerterp, K.R., Van Swaaij, W.P.M., Beenackers, A.A.C.M., Chemical Reactor Design and Operation, Wiley, New York 1984.

[5] Oyevaar, M.H., Morssinkhof, R.W.J., Westerterp, K.R., J. Chem. Eng Data 34 (1989a) pp. 77-82.

[6] Oyevaar, M.H., Fontein, H.J., Westerterp, K.R., J. Chem. Eng Data 34 (1989b) pp. 405-408.

[7] Oyevaar, M.H., Morssinkhof, R.W.J., Westerterp, K.R., Chem. Eng Sci. 45 (1990) pp. 3283-3298.

[8] Shulman, H.L., Ulirich, C.F., Wells, N., AIChE J. I (1955) pp. $247-264$.

[9] Gianetto, A., Baldi, G., Specchia, V., Sicardi, S., AIChE J. 24 (1978) pp. $1087-1104$.

[10] Sai, P.S.T., Varma, Y.B.G., Can. J. Chem. Eng 66 (1988) pp. $353-360$.

[11] Wammes, W.J.A., Middelkamp, J., Westerterp, K.R., submitted to AIChE J.

[12] Talmor, E., AIChE J. 23 (1977) pp. $868-878$

[13] Hirose, T., Toda, M., Sato, Y., J. Chem. Eng Jpn. 7 (1974) pp. $187-192$.

[14] Levec, J., Sáez, A.E., Carbonell, R.G., AlChE J. 32 (1986) pp. $369-380$.

[15] Morsi, B.I., Midoux, N., Laurant, A., Charpentier, J.C., Int. Chem. Eng 22 (1982) pp. 142-151.

[16] Specchia, V., Baldi, G., Chem. Eng Sci. 32 (1977) pp. 515- 523.

[17] Rao, V.G., Ananth, M.S., Varma, Y.B.G., AIChE J. $29(1983) \mathrm{pp}$ $467-482$.

[18] Van Swaaij, W.P.M., Thesis, Univ. Eindhoven 1967.

[19] Wammes, W.J.A., Mechielsen, S.J., Westerterp, K.R., Chem. Eng Sci. 46 (1991) pp. $409-417$ 